\title{
Strength training as superior, dose-dependent and safe prevention of acute and overuse sports injuries: a systematic review, qualitative analysis and meta- analysis
}

\author{
Jeppe Bo Lauersen, ${ }^{1,2}$ Thor Einar Andersen, ${ }^{3}$ Lars Bo Andersen ${ }^{1,4}$
}

\begin{abstract}
- Additional material is published online only. To view please visit the journal online (http://dx.doi.org/10.1136/ bjsports-2018-099078).

${ }^{1}$ Department of Sports Medicine Norwegian School of Sport Sciences, Oslo, Norway ${ }^{2}$ Department of Orthopedic Surgery, Hvidovre Hospital, Hvidovre, Denmark

${ }^{3}$ The Norwegian School of Sport Sciences, Oslo Sports Trauma Research Center, Oslo, Norway ${ }^{4}$ Faculty of Education, Arts and Sports, Western Norway University of Applied Sciences, Sogndal, Norway
\end{abstract}

\section{Correspondence to}

Dr Jeppe Bo Lauersen, Department of Sports Medicine, Norwegian School of Sport Sciences, Oslo 0863, Norway; jblau@dadlnet.dk

Accepted 23 July 2018 Published Online First 21 August 2018
ABSTRACT

Objective This review aims to analyse strength trainingbased sports injury prevention randomised controlled trials (RCT) and present best evidence recommendations for athletes and future research. A priori PROSPERO registration; CRD42015006970.

Design Systematic review, qualitative analysis and meta-analysis. Sorting of studies and quality assessments were performed by two independent authors. Qualitative analyses, relative risk (RR) estimate with robustness and strength of evidence tests, formal tests of publication bias and post-hoc meta-regression were performed.

Data sources PubMed, Embase, Web of Science and SPORTDiscus were searched to July 2017.

Eligibility criteria for selecting studies RCTs on strength training exercises as primary prevention of sports injuries.

Results Six studies analysed five different interventions with four distinct outcomes. 7738 participants aged 12-40 years were included and sustained 177 acute or overuse injuries. Studies were published in 2003-2016, five from Europe and one from Africa. Cluster-adjusted intention-to-treat analysis established RR 0.338 (0.2380.480). The result was consistent across robustness tests and strength of evidence was high. A 10\% increase in strength training volume reduced the risk of injury by more than four percentage points. Formal tests found no publication bias.

Conclusion The included studies were generally well designed and executed, had high compliance rates, were safe, and attained consistently favourable results across four different acute and overuse injury outcomes despite considerable differences in populations and interventions. Increasing strength training volume and intensity were associated with sports injury risk reduction. Three characteristically different approaches to prevention mechanisms were identified and incorporated into contemporary strength training recommendations.

\section{INTRODUCTION}

Exercise constitutes a cornerstone in the quality of life of recreational athletes, prevention of metabolic and frailty syndromes and in the worldwide elite sports entertainment business. ${ }^{12}$ Effective prevention of sports injuries, as the sole prevalent adverse effect of physical activity, could potentially benefit a wide spectrum of individuals involved in any form of exercise. ${ }^{3-6}$ While the management of sports injuries can be troublesome, time-consuming and expensive, prevention in the form of strength training has proved to be accessible, effective and cost-effective for populations. ${ }^{7-11}$ However, research has yet to establish fundamental strength training prevention mechanisms and parameters for optimization.

In 2013, Lauersen et $\mathrm{al}^{7}$ quantitatively compared the preventive effects of different types of exercise programmes: strength training, proprioception, stretching and multicomponent interventions. The obvious next step would be a further description and qualitative analysis of these four intervention types. However, several reviews have satisfactorily analysed both proprioception and stretching studies, ${ }^{12-15}$ while multicomponent programmes have proved problematic to analyse qualitatively due to their complex nature. ${ }^{16}{ }^{17}$ Therefore strength training, which proved the most effective, represented the logical progression and, to our knowledge, existing strength training research has primarily focused on biomolecular aspects, fall prevention in the elderly, general health gains or specific musculoskeletal injuries. Analysis of study design and execution, content of strength training interventions, injury outcomes, intervention safety and extraction of potential general prevention principles should enable the formulation of clinically relevant conclusions and best evidence recommendations for both contemporary prevention programmes and future research. As the current literature and guidelines are not fully developed, the aims of this review were to systematically identify and analyse qualitatively and quantitatively randomised controlled trials (RCTs) of strength training-based sports injury prevention programmes.

\section{METHODS}

\section{Search strategy, study selection and qualitative} analyses

A review protocol was registered in PROSPERO (CRD42015006970) in September 2015 (see online supplement section $\$ 1$ ), comprising a priori specification of analyses, study inclusion/exclusion criteria (table 1), injury definitions for study selection (see online supplement section $\$ 2)^{18} 19$ and complete search strategy (see online supplement section $\$ 3$ ). The PubMed, Embase, Web of Science and SPORTDiscus electronic databases were updated from October 2012 to 19 July 2017 and added to an existing search result, ${ }^{7}$ as shown in the study selection flowchart (figure 1). The search contained four blocks of keywords related to exercise programmes, 
Table 1 A priori specified criteria for title, abstract and full-text screening

\begin{tabular}{ll}
\hline Inclusion criteria & Exclusion criteria \\
\hline Strength training intervention & Intervention elements other than \\
Primary prevention of sports injuries & strength training \\
Sports injury data and/or analysis & Influencing pathology (eg, relevant \\
Trial participants free of injury at & previous injury, connective tissue \\
inclusion & disease, arthritis) \\
Randomised controlled trial & Surrogate measures of injury (eg, \\
Adequate/sufficient volume, intensity & reduced range of motion, radiology \\
and character of intervention & diagnosis only) \\
Adequate follow-up period for strength & Any use of devices (eg, \\
training to have effect (estimated to & kinesiotaping, protectors, orthoses, \\
1-2 months) & insoles) \\
Conducted in humans & Any means of transportation (eg, \\
Reported in English & bicycles, skis, equestrian) \\
Peer-reviewed publications & Inadequate design of control arms \\
\hline
\end{tabular}

prevention, injury and diagnoses, and RTCs combined with 'AND'. Reference lists in the selected studies were manually searched for eligible studies and a search was conducted in ClinicalTrials.gov. The original search strategy was designed with the assistance of a librarian.

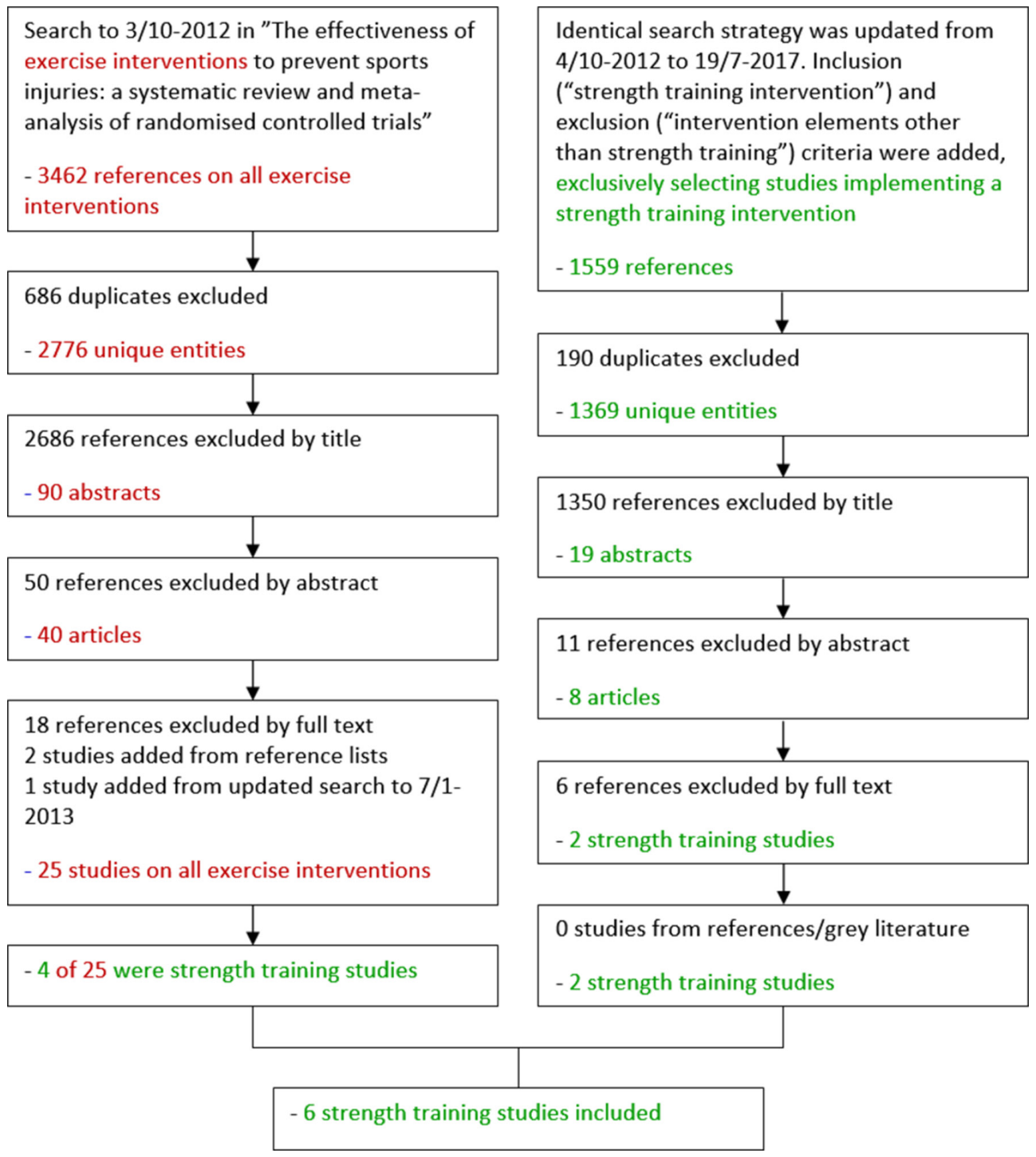

Figure 1 Study selection flowchart.
Two reviewers (JBL and LBA) independently screened all titles, abstracts and full-text articles and assessed risks of bias in the included studies using the domain-based evaluation tool recommended by the Cochrane Collaboration. ${ }^{20}$ Sorting and assessment discrepancies were resolved through discussion. Qualitative data were extracted from study reports and the corresponding authors were contacted by email in cases where additional information (both quantitative and qualitative) was required.

\section{Quantitative analyses}

Meta-analysis relative risk (RR) estimates, including all injury types, were calculated in Stata 12. Studies with incorrect analysis of cluster randomisation were adjusted and the strength of evidence was evaluated using GRADEpro. ${ }^{21} 22$ To achieve cluster adjustment, an intracluster correlation coefficient $(\rho)$, based on a $\rho$ value averaged from sports injury prevention studies appropriately adjusting for clustering effects, was computed as described in Lauersen et al. ${ }^{7}$ We assessed heterogeneity using $\mathrm{I}^{2}$, calculated from the Stata $\mathrm{Q}$-value, and number of studies (n) by $\mathrm{I}^{2}$ $=(\mathrm{Q}-(\mathrm{n}-1)) / \mathrm{Q}$. A rough interpretation guide of $\mathrm{I}^{2}$ has been proposed by Higgins et al. ${ }^{23}$ Publication bias was formally tested by Harbord's small-study effects test, a modified Galbraith's

Identical search strategy was updated from Inclusion "strength training intervention") and exclusion ("intervention elements other than strength training") criteria were added, exclusively selecting studies implementing a strength training intervention

- 1559 references

190 duplicates excluded

- 1369 unique entities

1350 references excluded by title

abstracts

11 references excluded by abstract

-8 articles

6 references excluded by full text

- 2 strength training studies

0 studies from references/grey literature

-2 strength training studies 


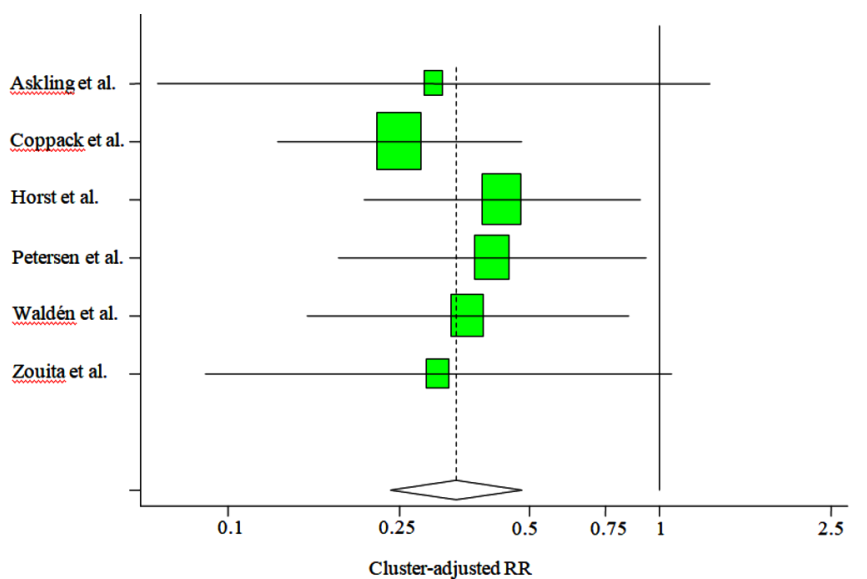

Figure 2 Forest plot of included strength training sports injury prevention programmes.

plot and a funnel plot. To assess the robustness of the results we performed subgroup analyses on age groups, blinding, intervention type and outcomes together with a meta-regression on the total assessed study quality.

A post hoc meta-regression of strength training volume (repetitions/week), intensity (xRM) and intervention duration (weeks) was performed to test for a dose-response relationship between strength training parameters and injury prevention effect. The model included all three variables with mutual adjustment. Logarithmic transformation of volume data eliminated skewness, enabling a correct meta-regression. Volumes and intensities were computed as averages and eccentric-only exercises as half of repetitions, but at $115 \%$ intensity, compared with exercises including both concentric and eccentric load phases (see full specification of assumptions, calculations and quantification in online supplement sections $\$ 9.1$ and $\$ 9.2) .{ }^{2425}$

\section{RESULTS}

A systematic search yielded 1559 records, of which 190 were duplicates. We excluded 1350 records by title, 11 references were excluded by abstract and six were eliminated by full-text screening (figure 1). Hand searching of reference lists and a grey literature search found no further studies (full study selection specification in online supplement sections $\$ 4.1$ and $\$ 4.2$ ). Two articles were added to the four strength training studies from Lauersen et $a l^{7}$, so six studies were finally included in our systematic review.

The six studies included 7738 participants aged 12-40 years with 177 observed injuries. Four studies analysed acute outcomes, ${ }^{26-29}$ one an overuse outcome ${ }^{30}$ and one study analysed all injuries ${ }^{31}$ (see online supplement section $\$ 5$ for a detailed description of study characteristics). On the basis of a lack of cluster adjustment, the power of the study by van der Horst et $a l^{27}$ was reduced by an inflation factor of 1.59 . The cluster-adjusted and intention-to-treat analysed relative risk (RR) estimate of the six included studies was 0.338 (95\% CI 0.238 to 0.480 , $\mathrm{P}<0.0001, \mathrm{I}^{2}=0 \%, \mathrm{P}=0.910$ ) (figure 2).

GRADEpro analysis found a 'high certainty' of evidence (see online supplement section \$7). Neither subgroup analyses of age (adults vs adolescents), blinding (participant and/or assessor blinded vs non-blinded), intervention type (hamstring training vs 'other') and outcomes (acute vs overuse injuries) nor meta-regression of total assessed study quality showed significant differences.
Harbord's small-study effect test $(P=0.425)$, the modified Galbraith plot (online supplement section \$8.1) and symmetric funnel plot (online supplement section $\$ 8.2$ ) found no indications of publication bias.

\section{Design of included studies}

The study populations, power and follow-up periods showed considerable differences between the six strength training studies. The study by Coppack et $a l^{30}$ analysed 1502 military conscripts while the remaining five studies included soccer players of various ages and levels. Askling et $a l^{26}$ and Zouita et al, ${ }^{31}$ respectively, included 30 adult elite players and 54 youth elite players in individual randomised studies while the remaining studies performed team cluster-randomised designs. Van der Horst et $a l^{27}$ included 648 amateur male soccer players, Petersen et $a l^{28} 942$ mixed amateur and elite players and Waldén $e a^{29}$ included 4564 female adolescent players. In the study by Coppack et $a l^{30}$ the follow-up period was restricted to 14 weeks due to military commitments while, in the other five studies, participants were followed up for one season, ranging from 7 to 12 months.

\section{Risk of bias assessment}

Apart from the difficulties in achieving participant and/or outcome assessor blinding, no compromising risks of bias were identified. Several studies made efforts to achieve blinding. We considered the studies by Askling et al, ${ }^{26}$ Coppack et al ${ }^{30}$ and Waldén et $a l^{29}$ to have a low risk of detection bias, and the study by Coppack et $a l^{30}$ to have a low risk of performance bias (for risk of bias specification see figure 3 and online supplement section \$6). The studies by Coppack et al, ${ }^{30}$ Petersen et $a l^{28}$ and Waldén et $a l^{29}$ made appropriate statistical adjustments for their cluster-randomised designs (low risk of 'other bias'), but the study by van der Horst et $a l^{27}$ did not (high risk of 'other bias'). The six studies either conducted intention-totreat analyses or had no missing data, thus having a low risk of attrition bias.

\section{Compliance}

Compliance was most frequently achieved through education of coaches, written material or supervision of training sessions (table 2). The qualifications of the supervisors ranged from one-day familiarisation of army instructors to experienced medical professionals. Askling et $a l^{26}$ reported full compliance with the intervention training programme (ie, all players attended all training sessions). Coppack et $a l^{30}$ (participation in sessions), van der Horst et $a l^{27}$ (registration of performed exercises) and Petersen et $_{a l^{28}}$ (registration of performed exercises) all reported compliance of $91 \%$. The studies by Waldén et $a l^{29}$ and Zouita et $a l,{ }^{31}$ respectively, had coaches and players document strength training participation to improve compliance and adherence but did not report these or any other compliance measures.

Notable factors to facilitate compliance and technique were used by Waldén et $a l^{29}$ who performed regular spot tests, van der Horst et $a l^{27}$ who held evaluation meetings and designed a website and Zouita et $a l^{31}$ who included variation elements to a tightly scheduled programme for young elite soccer players living at a Tunisian soccer centre.

\section{Interventions and outcomes}

Although all six studies designed interventions based on existing methodology and principles, the strength training programmes differed considerably between studies. The average volume (amount of exercise), average intensity (measured by number of 


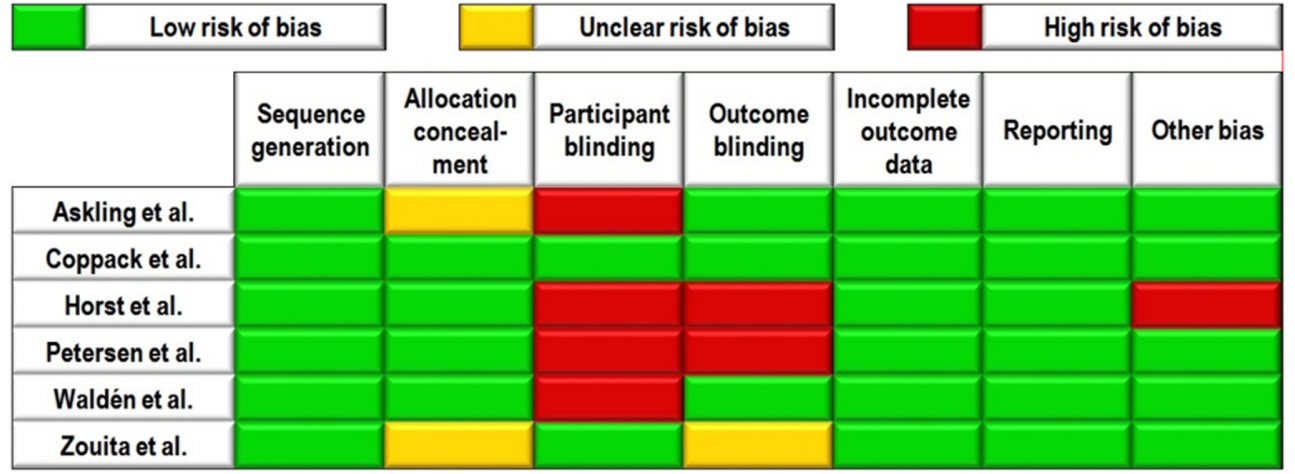

Figure 3 Summary of Cochrane domain-based quality assessment tool.

possible repetitions/sets in the form of $\mathrm{x}$ repetition maximum (xRM)) and mean (range) programme duration were 80.33 (11.7-253) repetitions/week, 8.39 (7.14-9.27) RM and 21.39 (10-39.93) weeks, respectively. RR estimates of included studies varied from $0.25(0.13-0.48)$ to $0.43(0.21-0.90)$.

Askling et $a l^{26}$ van der Horst et $a l^{27}$ and Petersen et $a l^{28}$ performed directly comparable pre-season hamstring programmes with the aim of preventing acute hamstring injuries in soccer players. Programme intensities and durations were similar, but the volumes (repetitions/week) differed. van der Horst et $l^{27}$ (11.7 repetitions/week), Petersen et $a l^{28}$ (18.9 repetitions/week) and Askling et $\mathrm{al}^{26}$ (64 repetitions/week) included increasing average volumes/week and correspondingly achieved decreasing RRs of $0.43(0.21-0.90), 0.41(0.18-0.93)$ and 0.30 (0.07-1.31), respectively. Petersen et $a l^{28}$ further implemented maintenance sessions once a week after the end of the pre-season programme. Askling et $a l^{26}$ differed from the two Nordic hamstring programmes by training-to-failure (not a fixed number but repetitions to exhaustion) and including both concentric and eccentric loads in flywheel exercises. van der Horst et $a l^{27}$ and Petersen $e t a l^{28}$ reported that no injuries occurred among their total of 753 participants during the Nordic hamstring exercises.

The remaining three studies performed appreciably different interventions and investigated different outcomes.

Coppack et $a l^{30}$ introduced a 14-week programme with four daily strength training exercises (plus minor elements of stretching) designed to invoke functional concentric and eccentric contractions of the hip and knee extensors to prevent overuse anterior knee pain in military recruits. Volumes and intensities were reported to increase through the intervention phases, but full specification was not given. The military recruits performed the largest volume of strength training among the included studies. A RR of $0.25(0.13-0.48)$ was achieved in relation to overuse anterior knee pain. There were no adverse events resulting from strength training among the 759 male and female recruits.

Table 2 Frequently implemented techniques to improve compliance and adherence

\begin{tabular}{|c|c|}
\hline Compliance measures & Implemented by \\
\hline Coach instruction & $\begin{array}{l}\text { Coppack et } a l_{,}^{30} \text { van der Horst et al }{ }_{1}^{27} \text { Petersen et al }{ }_{1}^{28} \\
\text { Waldén et } a{ }^{29}\end{array}$ \\
\hline Supervision & Askling et al ${ }_{1}^{26}$ Coppack et al ${ }_{1}^{30}$ Zouita et $a l^{31}$ \\
\hline Written material & Coppack et $a l_{,}^{30}$ van der Horst et al ${ }_{1}^{27}$ Petersen et a $\left.\right|^{28}$ \\
\hline Participant diary & Askling et $a l_{,}^{26}$ Zouita et $a \beta^{31}$ \\
\hline
\end{tabular}

Waldén et $\mathrm{al}^{29}$ applied a 20-min, whole-season, two sessions/ week balance, core stability and knee alignment programme to prevent acute anterior cruciate ligament (ACL) knee injuries (primary outcome). Both strength training in the classical sense (slow single-leg squat, slow bilateral squats and bench press) and coordination/joint proprioception-demanding dynamic exercises (pelvic lifts, lunges and jump/landing technique) were included and progressed in loads and coordination difficulty. No injuries among the 2479 12-17-year-old participants in the intervention group were attributed to strength training. The programme was performed twice/week for a full season and the RR estimate was $0.36(0.15-0.85)$. There were no statistical differences concerning severe knee injuries or other knee injuries (secondary outcomes).

Zouita et $a l^{31}$ studied a 13-14-year-old population of elite soccer players with sports injury as a secondary outcome. The intervention distinctively incorporated technique familiarisation, individualised load and progression calculations, goal-specific phases and periodisation, inter-phase recovery weeks and programme variation (to avoid monotony and performance plateaus), together with forced repetitions (completion of all sets even if assistance was required). Thirty-six sessions of 10 exercises (including squats, bench press, push-ups and sit-ups) were performed for $90 \mathrm{~min}$ with loads ranging from initial 30\% 1RM to $80 \% 1 \mathrm{RM}$ in the concluding high-intensity phase. The full programme specification was unspecified. Exercise velocity, intensity, technique, safety and rest periods were supervised by a physical coach. They defined injury as time loss exceeding 3 days but reported no statistical analyses. ${ }^{31}$ Based on reported participant and injury data, RR $0.31(0.09-1.07, \mathrm{P}=0.06)$ was calculated. Registered injuries were predominantly in the lower limbs, accounting for time losses from training/match of 18 and 147 hours for the intervention and control groups, respectively.

\section{Dose-response meta-regression}

The study by Zouita et al was excluded from calculations on the basis of insufficient data and author correspondence.

In co-analysis meta-regression, intervention duration was not significant $(\beta=-0.079, \mathrm{P}=0.065)$ while increasing ln(volume/ week) $(\beta=-1.365, P<0.005)$ and intensity $(\beta=1.971, P<0.005)$ correlated significantly with sports injury prevention. A $10 \%$ increase in the number of strength training repetitions was associated with a 4.3 percentage point (and 13\% relative) risk reduction, from RR $0.338(0.238-0.480)$ to RR 0.295 (0.208-0.419), assuming programme intensity and duration were constant. 
Mechanisms for prevention of acute and overuse injuries

Acute/overuse definitions are shown in online supplement section $\$ 2 .{ }^{32}$ Only Coppack et al ${ }^{30}$ supplied full and separate information on overuse and acute injuries in the knee and ankle joints. Zouita $e{ }^{2} l^{31}$ included a table of mixed acute and overuse injuries; however, the specification of four 'recurrent' injuries (equally distributed between study groups) was not available.

Four studies analysed acute injuries. The rationale of the three hamstring studies ${ }^{26-28}$ was a simple and direct strengthening of the frequently injured muscle, while the ACL injury prevention study ${ }^{29}$ primarily aimed at improving strength and coordination of the knee, pelvis and core. In all four studies a significant reduction in the acute sports injuries in question was achieved.

Coppack et $a l^{30}$ analysed overuse anterior knee pain, defined as aggravation of localised pain by repetitive and compressive forces. Strength training was performed in addition to initiation of a basic military programme for first-phase recruits and aimed at restoring patellar alignment in the femoral groove to avoid localised excessive joint loads and optimising quadriceps function. Besides reducing anterior knee pain by $75 \%$ in the intervention group, other injuries of the knee and ankle showed a generally mixed picture. Zouita $e t \mathrm{al}^{31}$ addressed the risk of overuse injuries by implementing a familiarisation phase, individualised programmes, recovery weeks and variation, but reported no distinct data on overuse injuries.

\section{DISCUSSION}

Six original RCTs reported five different strength training interventions and four distinct outcomes. The studies were published in 2003-2016, five studies from Europe and one from Africa. Four of the studies presented correctly analysed effect estimates. Implementation of the strength training interventions varied across the studies, but consistently showed a unique potential to prevent acute and overuse sports injuries.

An $\mathrm{I}^{2}$ score of $0 \%$ indicates low statistical heterogeneity in study outcomes. Neither Harbord's small-study effects test $(\mathrm{P}=0.425)$, the modified Galbraith's plot nor funnel plots indicated publication bias across the field of strength training interventions to prevent sports injuries.

\section{Design, risk of bias and compliance}

Substantial power differences between the studies were found. As statistical power relies on the number of injuries, injury prevention studies require a large number of participants as the injuries are often relatively infrequent and team-based cluster designs deflate power further. ${ }^{33}$

All six RCTs had strengths and limitations. The gold standard study would comprise Waldén et al's ${ }^{29}$ population size, van der Horst et al' $\mathrm{s}^{27}$ compliance-enhancing measures, Zouita et al' $\mathrm{s}^{31}$ intervention thoroughness, Askling et al's ${ }^{26}$ intervention description, Petersen et al's ${ }^{28}$ intervention duration and Coppack et al' $\mathrm{s}^{30}$ injury specification.

Quality, design and compliance rates of the included studies were generally convincing. ${ }^{7}$ Considering demanding blinding conditions due to the nature of the interventions, successful participant blinding in one study and outcome blinding in three studies is respectable. ${ }^{34}$ All injuries were assessed by medical professionals.

In view of the time consumption and effort needed for a strength training intervention, the four reported compliance rates were high. ${ }^{356}$ Zouita et al, ${ }^{31}$ in our view, implemented a theoretically optimal design for compliance optimisation although not reporting a compliance measure. While compliance in research settings was satisfactory, a challenge still persists in club adherence. ${ }^{3738}$ One suggestion to improve compliance and adherence could be to emphasise the fact that strength training prevention programmes may also improve sport-specific performance. ${ }^{39}$

\section{Interventions and outcomes}

Strength training programmes reduced sports injuries by an average of $66 \%$ and were, with $95 \%$ certainty, able to more than halve the risk of sports injury (95\% CI 52\% to 76\%). Coppack et $a l,{ }^{30}$ Horst $e t a l,{ }^{27}$ Petersen $e t ~ a l^{28}$ and Waldén $e t ~ a l^{29}$ reported no adverse events among their total of 3991 individuals during or due to the strength training interventions. With an average of more than 8 months of programme intervention in these four studies, we perceive this as a noteworthy accomplishment. Both our qualitative and quantitative analyses are in agreement with the literature that strength training is safe for children and adolescents and adds to the existing evidence by establishing that preparatory strength training also prevents acute and overuse injuries in adolescents. ${ }^{8} 4041$

Petersen $e t a l^{28}$ and Waldén $e t a l^{29}$ intervened throughout a whole season while Askling et al, ${ }^{26}$ Coppack et al,${ }^{30}$ van der Horst et $a l^{27}$ and Zouita $e t a l^{31}$ all intervened for 10-14 weeks with a typically greater volume of strength training. Van der Horst et $a l^{27}$ neither implemented a prolonged intervention period nor an intensive strength training programme and achieved the least favourable result, although a $43 \%$ reduction in injury is in no way negligible. From the three directly comparable studies, Askling et $a l^{26}$ reported slightly better compliance, included concentric contractions and greater volume and intensity of strength training than the Nordic hamstring programmes studies by van der Horst $e t a l^{27}$ and Petersen $e t a l,{ }^{28}$ which instead intervened over longer periods of time. The study by Askling et al achieved the most favourable RR estimate.

\section{Dose-response meta-regression}

Co-analysis meta-regression of all studies other than that of Zouita et al reached significance for volume/week and intensity, but not intervention duration. This strongly indicates that future studies and prevention programmes should comprise significant volumes and intensities of strength training to increase the prevention effect (while not neglecting to consider too abrupt increases and consequent risks of overuse injuries). Regarding programme duration, it remains unknown whether the weaker correlation is due to lower compliance, physiological reasons or other factors. The dose-dependent prevention effect was quantitatively expressed for clarity and layman communication purposes (see later section on Strength training recommendations for further clinical considerations).

Other parameters or conditions hypothesised to influence strength training results are rest times between sets, rest times between sessions, periodisation, exercise range of motion and execution speed. ${ }^{42}$ Further research, including full and consistent reporting of intervention characteristics, is needed to address these additional factors.

\section{Mechanisms for prevention of acute and overuse injuries}

As with the sports injury prevention field in general, most strength training studies have shortcomings regarding full injury specification and distinction between acute and overuse injuries.

Acute sports injuries were successfully reduced by two contrasting mechanisms. Three hamstring studies showed a direct effect of strength training in preventing acute hamstring muscle injuries. Waldén et $a l^{29}$ achieved a $64 \% \mathrm{ACL}$ injury reduction 
by a seemingly indirect mechanism, focusing on improved core stability, pelvis control and extremity coordination. ${ }^{43-45}$ We hypothesise that the indirect acute injury prevention effect works through mechanisms of strength training-related carryover effect with improved coordination, enhanced technique in training/match situations, strengthening of adjacent tissues reducing critical joint loads and better psychological perception of high-risk situations. ${ }^{346}$

Regarding overuse injuries, Coppack et al, ${ }^{30}$ apart from the primary overuse anterior knee pain reduction of $75 \%$, showed generally mixed and not statistically analysed results. It is worth noting the volume of seven sessions/week and programme introduction concurrent with military training, considering that gradual increases in loads, remodelling capacity and vascularisation are thought to be important factors in tissue anabolism/ catabolism balances and therefore overuse injuries. ${ }^{47-55}$ These results point towards the patellar alignment theory, ${ }^{56}$ which is hypothesised to alleviate localised overuse stresses at the joint cartilage, being effective, while the design may be suboptimal for overuse injury prevention in general. Zouita $e t a l^{31}$ designed thoughtful gradual load progressions but unfortunately did not provide specific overuse injury data for evaluation. Although fully individualised programmes and physical coach-supervised forced repetitions may be unattainable in most large-scale studies, parameters such as familiarisation, athlete/coach individualised workload education, goal-specific progressive phases, appropriate variation and recovery measures should be realistic considerations.

These studies support the notion that overuse injuries occur when tissues are chronically overloaded, and we suggest that preventive mechanisms, besides simply evading pain triggers or reducing the amount of training/competition in burdened periods, could include preconditioning, tissue-relieving variation in exercises and loads, and carry-over of improved coordination/technique from a strength training prevention programme, potentially beneficially altering load distributions in the tissues and joints. ${ }^{304655}$

\section{Strength training recommendations}

Although strength training evidence and programmes are continuously developing, contemporary principles and recommendations remain important for current athletes and in directing future research.

Based on the included studies, we recommend a familiarisation/technique phase prior to gradual volume and intensity progressing phases. This approach will address key parameters and mechanisms for acute and overuse injuries for both the strength training intervention and the often concurrent participation in sport or other physical activities. The evidence clearly points towards strengthening failure thresholds of relevant tissues, sufficient technique and psychological preparedness to prevent acute injuries ${ }^{34}$ and gradual tissue conditioning, sufficient technique and training variation to prevent overuse injuries. $^{304655}$ Preliminary phases may seem irrelevant to eager athletes/clubs, however we consider the initial phases of injury prevention to be a critical investment, especially as injuries inevitably constitute delays and setbacks in relation to the very same goals as the original sport participation. ${ }^{55} 5758$ Initiation in off-season or less demanding periods would be advantageous, especially in relation to overuse injuries. Additionally, interventions have been shown to prevent injuries and also to improve sport performance, which is an important aspect for coaches and athletes. ${ }^{639}$
Thorough consideration should be given to sufficient programme volumes and intensities. The dose-response relationship found in our analyses supports the hypothesis that strength improvement and injury prevention are closely related. ${ }^{59} 60$ Neither qualitative nor quantitative analyses showed that children and adolescents warrant significantly different approaches; however, we recommend avoidance of explosive loads together with at least equal emphasis on qualified instruction, competent supervision, appropriate volume and intensity progression as in adults. ${ }^{8041}$ Supervision, short-term periodisation, longterm variation, \%RM-individualised loads and appropriate rest periods can profitably be incorporated. ${ }^{42} 6162$ Heavy weight training as a warm-up before other athletic activities cannot be recommended as the resulting fatigue may both be detrimental to performance and increase the risk of injuries. ${ }^{4255}$ The recommended rest period between maximal efforts is approximately 72 hours for beginners, with experienced and physiologically adapted athletes likely needing shorter recovery times. ${ }^{425563} \mathrm{We}$ hypothesise that completion of this approach over successive seasons will afford incremental carry-over gains in prevention effectiveness as reductions of modifiable risk factors accumulate.

\section{Perspectives}

Aetiological factors of sports injuries suggested in the literature to be susceptible to injury prevention measures are muscular imbalance (eg, low hamstring:quadriceps strength ratio), muscle fatigue, muscle tightness, insufficient warm-up and previous injuries. ${ }^{64-69}$ These risk factors have further been presumed to be additive, and exceeding a threshold of cumulating risk factors has been hypothesised to result in an injury. ${ }^{59} 70$ Similar aetiological factors have been proposed for ankle injuries and may even be applicable to multiple/all sports injuries. ${ }^{71}$

Insufficient strength of the vaguely defined 'core muscles' has been proposed as an important risk factor of groin strains and possibly other injuries on the basis of poor biomechanical translation of loads, illustrating the complexity of sports injuries. ${ }^{72}$ Future sports injury prevention studies should keep the factor of core strength in mind when including individuals and designing interventions if we are to incorporate it relevantly into our understanding of sports injuries. Adding to the intricacy of acute sports injuries is the question of individual cognitive and spatial capabilities, postural balance and coordination skills, and new research areas such as functioning muscle chains and the role of coherent muscle fasciae throughout the whole body. ${ }^{774}$

\section{Strength and limitations}

This review registered a priori specification of aims and methods in PROSPERO (CRD42015006970). We adhered to AMSTAR, MOOSE and PRISMA guidelines, determined meta-analysis strength of evidence using GRADEpro and tested for publication bias. ${ }^{75}$ Certainty of Harbord's small-study effects test requires 10 included studies, and a funnel plot was produced for additional visual assessment of publication bias. Study selection and the Cochrane domain-based risk of bias assessment were conducted by two independent researchers. Only English manuscripts were included, which increases the risk of language bias.

Incorrect cluster-randomisation analysis of original studies was adjusted in accordance with the mathematics of Emery et $\mathrm{al}^{21}$ and an assumption of team size in team sports to be relatively similar. ${ }^{22}$ Although potentially rendering the estimate by van der Horst $e a^{l^{27}}$ to be slightly imprecise, this is preferable to the alternative vast overestimation of study power, frequently in the range of a factor 2-3. We consider this correction of included 
data to be a notable strength of our meta-analysis. Our subgroup analyses of RR estimates to assess consistency of results should be carefully interpreted due to limited statistical power. However, neither significant differences nor tendencies were found and we consider our results to be robust to age, study blinding, study quality, intervention and injury type.

We consider the explicit quantification of the dose-response relationship to be a strength in relation to scientific evaluation of interventions, communication with lay people and, in turn, potentially their motivation to adhere to the intervention. However, such calculations can only be considered valid within the range of the included data. We did not quantify strength training intensity as a narrow range of 6.9-9.3RM was likely to result in an imprecise estimate.

Although five of the six included studies enrolled populations of football players, both the included evidence and the literature point towards plausible and general mechanisms that make these findings externally valid. ${ }^{76}$ While exercises can be claimed to be site-specific and injuries of interest to be sport-specific, the mechanisms and cause of effect most likely cannot. Although the evidence for strength training would still benefit from further and broader research, we consider the included studies to be similar enough to compare, and different enough to elicit generally applicable conclusions. Put into perspective, we believe the evidence provided in this article is sufficient to warrant a paradigm shift from the current dominance of multicomponent prevention programmes towards strength training programmes as the primary intervention to prevent sports injuries.

\section{CONCLUSION}

Despite differing with regard to populations, interventions and analyses, all six included studies were of high quality and demonstrated a dose-response relationship between strength training and sports injury prevention. In addition to being very safe, these interventions have-through more than one

\section{What is already known?}

- Strength training programmes to prevent acute and overuse sports injury are effective.

- Neuromuscular training and multicomponent programme studies are effective, but to a lesser degree than strength training programmes.

- The number of studies exclusively analysing strength training interventions is increasing.

\section{What are the new findings?}

- Strength training injury prevention studies are of generally convincing quality.

- Despite noticeable differences in populations and interventions, strength training attained consistently favorable results across four different acute and overuse injury outcomes.

- Nearly 4000 individuals performed interventions for several months without a single adverse event being accredited to strength training interventions.

- Three characteristically different approaches to prevention mechanisms were identified.

- A dose-response between strength training and the preventive effect on sports injuries. mechanism-proven prevention results seldom achieved by other exercise interventions or fields of medicine.

Contributors All persons who meet authorship criteria are listed as authors, and all authors certify that they have participated sufficiently in the work to take responsibility for the content, including participation in the concept, design, analysis, writing, or revision of the manuscript.

Funding The authors have not declared a specific grant for this research from any funding agency in the public, commercial or not-for-profit sectors.

Competing interests None declared.

Patient consent Not required.

Provenance and peer review Not commissioned; externally peer reviewed.

\section{REFERENCES}

1 Sundell J. Resistance training is an effective tool against metabolic and frailty syndromes. Adv Prev Med 2011;2011:1-7.

2 Warburton DE, Nicol CW, Bredin SS. Health benefits of physical activity: the evidence. CMAJ 2006;174:801-9.

3 Bahr R, Krosshaug T. Understanding injury mechanisms: a key component of preventing injuries in sport. Br J Sports Med 2005;39:324-9.

4 van Gent RN, Siem D, van Middelkoop M, et al. Incidence and determinants of lower extremity running injuries in long distance runners: a systematic review. Br I Sports Med 2007;41:469-80.

5 Lavallee ME, Balam T. An overview of strength training injuries: acute and chronic. Curr Sports Med Rep 2010;9:307-13.

6 Drew MK, Raysmith BP, Charlton PC. Injuries impair the chance of successful performance by sportspeople: a systematic review. Br I Sports Med 2017:51:1209-14.

7 Lauersen JB, Bertelsen DM, Andersen LB. The effectiveness of exercise interventions to prevent sports injuries: a systematic review and meta-analysis of randomised controlled trials. Br J Sports Med 2014;48:871-7.

8 Faigenbaum AD, Myer GD. Resistance training among young athletes: safety, efficacy and injury prevention effects. Br I Sports Med 2010;44:56-63.

9 Campbell K, Foster-Schubert K, Xiao L, et al. Injuries in sedentary individuals enrolled in a 12-month, randomized, controlled, exercise trial. J Phys Act Health 2012;9:198-207.

10 Marshall DA, Lopatina E, Lacny S, et al. Economic impact study: neuromuscular training reduces the burden of injuries and costs compared to standard warm-up in youth soccer. Br I Sports Med 2016:50:1388-93.

11 Janda DH. Sports injury surveillance has everything to do with sports medicine. Sports Med 1997;24:169-71.

12 Herman K, Barton C, Malliaras P, et al. The effectiveness of neuromuscular warm-up strategies, that require no additional equipment, for preventing lower limb injuries during sports participation: a systematic review. BMC Med 2012;10:75.

13 Hübscher $M$, Zech A, Pfeifer $K$, et al. Neuromuscular training for sports injury prevention: a systematic review. Med Sci Sports Exerc 2010;42:413-21.

14 Herbert RD, Gabriel M. Effects of stretching before and after exercising on muscle soreness and risk of injury: systematic review. BMJ 2002:325:468.

15 Thacker SB, Gilchrist J, Stroup DF, et al. The impact of stretching on sports injury risk: a systematic review of the literature. Med Sci Sports Exerc 2004;36:371-8.

16 Soomro N, Sanders R, Hackett D, et al. The efficacy of injury prevention programs in adolescent team sports: a meta-analysis. Am J Sports Med 2016;44:2415-24.

17 Lauersen JB, Andersen LB. Multi-faceted exercise programs versus strength training to prevent sports injuries. J Xiangya Med 2017;2:34

18 Fuller CW, Ekstrand J, Junge A, et al. Consensus statement on injury definitions and data collection procedures in studies of football (soccer) injuries. Br J Sports Med 2006:40:193-201.

19 Bahr R. No injuries, but plenty of pain? On the methodology for recording overuse symptoms in sports. Br J Sports Med 2009:43:966-72.

20 Higgins JPT, Green S. Cochrane Handbook for Systematic Reviews of Interventions In: The Cochrane Collaboration. 2011 www.cochrane-handbook.org.

21 Emery CA. Considering cluster analysis in sport medicine and injury prevention research. Clin I Sport Med 2007;17:211-4.

22 Wears RL. Advanced statistics: statistical methods for analyzing cluster and clusterrandomized data. Acad Emerg Med 2002;9:330-41.

23 Higgins JP, Thompson SG. Quantifying heterogeneity in a meta-analysis. Stat Med 2002;21:1539-58.

24 Mike J, Kerksick CM, Kravitz L. How to incorporate eccentric training into a resistance training program. Strength Cond J 2015;37:5-17.

25 Moir GL, Erny KF, Davis SE, et al. The development of a repetition-load scheme for the eccentric-only bench press exercise. J Hum Kinet 2013;38:23-31.

26 Askling C, Karlsson J, Thorstensson A. Hamstring injury occurrence in elite soccer players after preseason strength training with eccentric overload. Scand J Med SCi Sports 2003;13:244-50. 
27 van der Horst N, Smits DW, Petersen J, et al. The preventive effect of the Nordic hamstring exercise on hamstring injuries in amateur soccer players: a randomized controlled trial. Am J Sports Med 2015;43:1316-23.

28 Petersen J, Thorborg K, Nielsen MB, et al. Preventive effect of eccentric training on acute hamstring injuries in men's soccer: a cluster-randomized controlled trial. Am J Sports Med 2011;39:2296-303.

29 Waldén M, Atroshi I, Magnusson H, et al. Prevention of acute knee injuries in adolescent female football players: cluster randomised controlled trial. BMJ 2012;344:e3042.

30 Coppack RJ, Etherington J, Wills AK. The effects of exercise for the prevention of overuse anterior knee pain: a randomized controlled trial. Am J Sports Med 2011;39:940-8.

31 Zouita S, Zouita AB, Kebsi W, et al. Strength training reduces injury rate in elite young soccer players during one season. J Strength Cond Res 2016;30:1295-307.

32 Yang J, Tibbetts AS, Covassin T, et al. Epidemiology of overuse and acute injuries among competitive collegiate athletes. J Athl Train 2012;47:198-204.

33 Bahr R, Holme I. Risk factors for sports injuries-a methodological approach. Br J Sports Med 2003;37:384-92.

34 Boutron I, Tubach F, Giraudeau B, et al. Blinding was judged more difficult to achieve and maintain in nonpharmacologic than pharmacologic trials. J Clin Epidemiol 2004;57:543-50.

35 Fortington LV, Donaldson A, Lathlean T, et al. When 'just doing it' is not enough: assessing the fidelity of player performance of an injury prevention exercise program. J Sci Med Sport 2015;18:272-7.

36 Burton $\mathrm{E}$, Lewin $\mathrm{G}$, Pettigrew $\mathrm{S}$, et al. Identifying motivators and barriers to older community-dwelling people participating in resistance training: a cross-sectional study. J Sports Sci 2017;35:1523-32.

37 McCall A, Carling C, Nedelec M, et al. Risk factors, testing and preventative strategies for non-contact injuries in professional football: current perceptions and practices of 44 teams from various premier leagues. Br J Sports Med 2014;48:1352-7.

38 Bahr R, Thorborg K, Ekstrand J. Evidence-based hamstring injury prevention is not adopted by the majority of Champions League or Norwegian Premier League football teams: the Nordic Hamstring survey. Br J Sports Med 2015;49:1466-71.

39 Faude 0 , Rössler R, Petushek EJ, et al. Neuromuscular adaptations to multimodal injury prevention programs in youth sports: a systematic review with meta-analysis of randomized controlled trials. Front Physiol 2017;8:791.

40 McCambridge TM, Stricker PR. Strength training by children and adolescents. Pediatrics 2008;121:835-40.

41 Faigenbaum AD. Strength training for children and adolescents. Clin Sports Med 2000;19:593-619.

42 Hartmann $\mathrm{H}$, Wirth $\mathrm{K}$, Keiner M, et al. Short-term periodization models: effects on strength and speed-strength performance. Sports Med 2015;45:1373-86.

43 Steffen K, Andersen TE, Krosshaug T, et al. ECSS Position Statement 2009: Prevention of acute sports injuries. Eur J Sport Sci 2010;10:223-36.

44 Wilkerson GB, Colston MA. A refined prediction model for core and lower extremity sprains and strains among collegiate football players. J Ath/ Train 2015;50:643-50.

45 Arendt EA. Core strengthening. Instr Course Lect 2007;56:379-84.

46 Myer GD, Ford KR, Palumbo JP, et al. Neuromuscular training improves performance and lower-extremity biomechanics in female athletes. J Strength Cond Res 2005;19:51-60.

47 Benjamin M, Hillen B. Mechanical influences on cells, tissues and organs 'Mechanical Morphogenesis'. Eur J Morphol 2003;41:3-7.

48 Khan KM, Scott A. Mechanotherapy: how physical therapists' prescription of exercise promotes tissue repair. Br J Sports Med 2009;43:247-52.

49 Schleip R, Müller DG. Training principles for fascial connective tissues: scientific foundation and suggested practical applications. J Bodyw Mov Ther 2013;17:103-15.

50 Kannus $P$, Józsa L, Natri A, et al. Effects of training, immobilization and remobilization on tendons. Scand J Med Sci Sports 1997;7:67-71
51 Kongsgaard M, Reitelseder S, Pedersen TG, et al. Region specific patellar tendon hypertrophy in humans following resistance training. Acta Physiol 2007;191:111-21.

52 Kubo K, Ikebukuro T, Yata $\mathrm{H}$, et al. Time course of changes in muscle and tendon properties during strength training and detraining. J Strength Cond Res 2010;24:322-31.

53 Kannus P, Sievänen $\mathrm{H}$, Vuori I, et al. Physical loading, exercise, and bone. Bone 1996; 18:S1-S3.

54 Kannus $\mathrm{P}$, Haapasalo $\mathrm{H}$, Sievänen $\mathrm{H}$, et al. The site-specific effects of long-term unilateral activity on bone mineral density and content. Bone 1994;15:279-84.

55 Wallden M. Designing effective corrective exercise programs: the importance of dosage. J Bodyw Mov Ther 2015;19:352-6.

56 Post WR, Teitge R, Amis A. Patellofemoral malalignment: looking beyond the viewbox. Clin Sports Med 2002:21:521-46.

57 Kraemer WJ, Fleck SJ, Evans WJ. Strength and power training: physiological mechanisms of adaptation. Exerc Sport Sci Rev 1996:24:363-97.

58 Nielsen RØ, Parner ET, Nohr EA, et al. Excessive progression in weekly running distance and risk of running-related injuries: an association which varies according to type of injury. J Orthop Sports Phys Ther 2014;44:739-47.

59 Pedersen MT, Andersen LL, Jørgensen MB, et al. Effect of specific resistance training on musculoskeletal pain symptoms: dose-response relationship. J Strength Cond Res 2013;27:229-35.

60 Peterson MD, Rhea MR, Alvar BA. Applications of the dose-response for muscular strength development: a review of meta-analytic efficacy and reliability for designing training prescription. J Strength Cond Res 2005;19:950-8.

61 Campos GE, Luecke TJ, Wendeln HK, et al. Muscular adaptations in response to three different resistance-training regimens: specificity of repetition maximum training zones. Eur J App/ Physiol 2002;88(1-2):50-60.

62 Stone MH. Muscle conditioning and muscle injuries. Med Sci Sports Exerc 1990;22:457-62

63 Hartmann $\mathrm{H}$, Bob A, Wirth K, et al. Effects of different periodization models on rate of force development and power ability of the upper extremity. J Strength Cond Res 2009:23:1921-32.

64 Agre JC. Hamstring injuries. Proposed aetiological factors, prevention, and treatment. Sports Med 1985;2:21-33.

65 Clanton TO, Coupe KJ. Hamstring strains in athletes: diagnosis and treatment. J Am Acad Orthop Surg 1998;6:237-48.

66 Coole WG, Gieck JH. An analysis of hamstring strains and their rehabilitation. J Orthop Sports Phys Ther 1987;9:77-85.

67 Drezner JA. Practical management: hamstring muscle injuries. Clin J Sport Med 2003;13:48-52.

68 Kujala UM, Orava S, Järvinen M. Hamstring injuries. Current trends in treatment and prevention. Sports Med 1997;23:397-404.

69 Worrell TW. Factors associated with hamstring injuries. An approach to treatment and preventative measures. Sports Med 1994;17:338-45.

70 Devlin L. Recurrent posterior thigh symptoms detrimental to performance in rugby union: predisposing factors. Sports Med 2000;29:273-87.

71 Baumhauer JF, Alosa DM, Renström AF, et al. A prospective study of ankle injury risk factors. Am J Sports Med 1995;23:564-70.

72 Maffey L, Emery C. What are the risk factors for groin strain injury in sport? A systematic review of the literature. Sports Med 2007:37:881-94.

73 Schleip R, Klingler W, Lehmann-Horn F. Active fascial contractility: fascia may be able to contract in a smooth muscle-like manner and thereby influence musculoskeletal dynamics. Med Hypotheses 2005;65:273-7.

74 Bere T, Flørenes TW, Krosshaug T, et al. A systematic video analysis of 69 injury cases in World Cup Alpine skiing. Scand J Med Sci Sports 2014:24:667-77.

75 Weir A, Rabia S, Ardern C. Trusting systematic reviews and meta-analyses: all that glitters is not gold!. Br J Sports Med 2016:50:1100-1.

76 McCrary JM, Ackermann BJ, Halaki M. A systematic review of the effects of upper body warm-up on performance and injury. Br J Sports Med 2015;49:935-42. 